\title{
The Evolution of Music-A Comparison of Darwinian and Dialectical Methods
}

\author{
Derek Gatherer
}

ABSTRACT

Music provides a challenging system for the analysis of cultural evolution. The dialectical approach to music seeks to identify the internal stylistic tensions and contradictions (in terms of thesis and antithesis) which give rise to new musical forms (synthesis). The Darwinian alternative to dialectics, which in its most reductionist form is becoming known as memetics, seeks to interpret the evolution of music by examining the adaptiveness of its various component parts in the selective environment of culture. This essay compares the memetic and dialectical approaches with special reference to the development of jazz in the era of recorded sound, in the light of Benzon's classification of musical styles into evolutionary Ranks (Benzon, 1993). This essay concludes that the basic postulate of memetics is falsifiable and therefore that memetics qualifies as scientific in the Popperian sense, rather than being simply a pscudo-scientific meta-narrative for cultural evolution. Some suggestions for empirical analysis are provided. In contrast, the dialectical perspective is not scientific in the Popperian sense, but does provide a good explanatory framework for the history of jazz in the years 1900-1970, and shows how transitions between "ranks" (from Benzon) may be generated. However, dialectics is considerably less successful in the construction of a model to explain the period since 1970 .

\section{Music as an Evolving System}

Musical styles, both compositional and interpretational, may change extensively within the lifetime of one individual. Western "classical" music has experienced an acceleration in this process throughout the 20th century (Griffiths, 1994). This has been paralleled in AfricanAmerican music (and its European derivatives) since the 1940s. On the other hand, some musical styles have remained relatively static, particularly those of non-Western cultures and those involved in ritual function. ${ }^{1}$ This property of variable rates of change over time and an overall, if erratic, tendency towards increasing complexity has many parallels with biological evolution. ${ }^{2}$ The question of evolution in music is part of a more general debate concerning the evolutionary properties of human culture as a whole.

Derek Gatherer, School of Biomolecular Sciences, Liverpool John Moores University, Liverpool L3 3 AF, United Kingdom. 
Cultural evolutionism, that is the tendency to consider human culture as an evolving phenomenon, has been an often controversial element in the fields of anthropology and sociology since Darwin's time (reviewed by Dobzhansky, 1961). Its present revival is not so much among social scientists as among biologists interested in culture, of whom Medawar (1959) may be given precedence. Further stimulus was provided by Cavalli-Sforza, Feldman and collaborators (reviewed by Cavalli-Sforza, 1986) from the early 1970s onwards, and the present radically Darwinian approach dates from Dawkins (1976).

Dawkins did not claim any originality for his ideas, but there is no doubt that he made a greater impact than his predecessors. This was principally due to two factors which were not present in previous reductionist approaches. First, he coined a new term for the unit of selection in cultural evolution, the "meme." This did not vary greatly from previous conceptions of "culturgen" (reviewed by Cavalli-Sforza, 1986) or "symbolate" (White, 1959/1962), but the deliberate pun on "gene" openly invited the direct transposition of the terminology and methods of evolutionary genetics to cultural studies, in a way that had not previously been contemplated. Dawkins' second contribution was his emphasis on "selfish" memes, in other words cultural entities which are effectively transmitted and increase in frequency even when they are maladaptive to the individuals that receive and transmit them. This concept was directly analogous to the study of "selfish" genes in biological systems. Thus Dawkins' novel slant transformed cultural evolutionism into memetics. ${ }^{3}$

Against cultural evolutionism, with its emphasis on variation, transmission, and selection, stands the dialectical tradition. This posits a triadic system of thesis-antithesis-synthesis as a mechanism of change. Selection has no role, and culture evolves under an internal propulsion. This motive force stems either from, in Hegelian dialectics, the "Authebung" of "Geist" (usually translated, not particularly helpfully, as the "diremption" of Absolute Spirit), or in the later Marxist dialectics from the interpenetration of culture with the substructure of the society in which it exists. ${ }^{4}$ In either case, the resulting process of change is the same. It should be emphasized at this stage that dialectics is not scientific, especially not when viewed from the Popperian position adopted by many scientists (Popper, 1959/1972). One would have to be a very recalcitrant Marxist to insist that it is. ${ }^{5}$ In its pre-Marxist, more purely Hegelian form, dialectics is a metaphysical system which is placed prior to science. One might wonder what value there is in comparing a non-scientific metaphysical system like dialectics with a putatively scientific one like memetics. The point of the exercise is that memetics, if it is genuinely scientific, must provide at least as good a fit to the data as dialectics, and furthermore must suggest falsifiable hypotheses and the means to investigate them. What is at issue is the claim that memetics can be a genuinely scientific approach to cultural evolution.

Although dialectics does produce evolution of sorts, it is not the kind of evolution that a Darwinian would recognize. There is no space for thesis and antithesis in memetics. However, the situation is complicated by the fact that a memeticist may posit economic or social forces as selective agents in cultural evolution, thus taking memetics into territory previously, and still to a certain extent, occupied by Marxists. What follows is an attempt to examine a well-known musical history, that of African-American jazz since the 1890s, in both memetic and dialectical terms, in the hope of finding evidence for or against either of the systems. The following brief and oversimplified summary is given for the benefit of those who are not familiar with the music. ${ }^{6}$ 


\section{Stylistic Progression in African-American Music}

The earliest recordings of African- $\Lambda$ merican music date from around the turn of the century. Vail (1993) suggests that the first jazz recording may be "Sounds from Africa" performed by Vess Ossman in New York City on the 8th of January, 1900. Oral tradition and written sources make it certain that a kind of music existed at least as far back as the $1890 \mathrm{~s}$, in New Orleans and other parts of the south, which is directly ancestral to what came to be known as jazz. Despite the famous claim made by Jelly Roll Morton (1890-1941) to have invented jazz in 1902 (Berendt, 1983, p.8), unrecorded musicians such as Buddy Bolden (1877-1931) and Jack Laine (1873-1966) were active in the late 19th century, playing a brass marching bandbased style in which the instrumentation was very similar to the later jazz bands, and many jazz elements such as improvisation may have figured prominently. This phase of largely pre-literate expressive culture is what William Benzon $(1993,1997)$ has described as Rank 1.

As the Southern rural workforce migrated north in the aftermath of the First World War, jazz split into two geographical zones, the original Southern variety and what became known by the 1920s as Chicago jazz. Increasing contact with White musicians resulted in the acquisition of Western musical notation. Jelly Roll Morton's "The King Porter Stomp" (1906) may be the first notated jaž composition (Hardy \& Laing, 1990). ${ }^{7}$. The roles of composer and performer were thus circumscribed with the space between left for improvisation. Compositional sophistication developed during the Swing era of the 1930s, corresponding to Benzon's Rank 2, and improvisational sophistication took an exponential leap with the advent of Bebop in the mid-1940s. By this time, jazz was nearly as harmonically sophisticated as the latest European classical music of the time, and considerably more so rhythmically. This corresponds to Benzon's Rank $3 .^{8}$

The 1950s saw another geographical split develop, this time between the Cool jazz of California and the Hard Bop style of New York and the Mid-West. Free jazz, dispensing with the strictures of key systems, and permitting total improvisatory freedom, arose in the late 1950s. This was simultaneously a step away from traditional European music and a step closer to the European classical avant-garde, at that time also preoccupied with atonality and improvisational "aleatoric" practices (Griffiths, 1994). Jazz was now equal in sophistication to European music in all aspects of composition and performance. The 1960 s saw a reaction to the avant-gardism of Free jazz which took several forms, firstly in the shape of Bossa Nova (which fused Cool with Brazilian music) and secondly in the growth of the parallel tradition of Soul, and Rock music. These shared many of the roots of jazz but de-emphasized the tendencies towards extreme technical sophistication and abstraction that had been apparent since early Bebop.

The 1970s produced Fusion, which attempted to reconcile the divergent traditions of jazz and Rock, but by the early 1980s the Fusion movement had disintegrated and many of its proponents had reverted to Bebop-based styles. Contemporaneously a third tradition, that of Rap and Hiphop, developed. The intricate use of studio technology in this tradition may place it in Benzon's Rank 4. ${ }^{9}$ European classical music, despite some technological experimentation among the Darmstadt group of composers in the $1960 \mathrm{~s}$, cannot be said to have reached a Rank 4 stage. African-American music thus represents a highly rapidly developing musical system, much of which is directly accessible to study via recordings. Unlike European classical music, there is no problem with "authenticity" in the interpretation of older works. 


\section{A Dialectical Approach}

Dialectics posits a system by which any idea constitutes a "thesis" which inevitably must have its contradiction or "antithesis." The opposition of these entities leads to "synthesis" in which their differences become a source of something qualitatively new. This synthesis is then considered as the new thesis and the process repeats itself. Suggestively for dialecticians, much of the history of African-American music has been characterized by often vehemently opposed schools, elements of which are then often found combined in a succeeding movement which is different to both its parental styles. The following examples may be cited:

(a) Swing (synthesis) emerged out of the opposition of New Orleans (thesis) and Chicago (antithesis) in the 1920s.

(b) Swing (thesis) was opposed by the more traditional Blues-oriented Jump style (antithesis) in the 1930s, from which emerged Bebop (synthesis).

(c) In the late 1950s and early 1960s, Hard Bop (thesis) was opposed by Free (antithesis), producing Freebop (synthesis).

(d) In the late 1960s Freebop (thesis) was opposed by Rock/Soul (antithesis) resulting in Fusion (synthesis).

(e) In the early 1980s, Fusion (thesis) was opposed by Post-Bop (antithesis), producing $\mathbf{M}$-base (synthesis).

It may be noted that (a) corresponds to Benzon's emergence of Rank 2, and (b) to the emergence of Rank 3. ${ }^{10}$

There are problems with this analysis. For instance, it is not easy to ascertain the dialectical conditions in the early 1950 s. Bebop as thesis was clearly opposed by Cool as antithesis, but no synthesis resulted. Instead Bebop solidified into Hard Bop (in much the same way as 1960s Rock stiffened into Heavy Metal) and a fresh antithesis to Hard Bop was produced in the form of Free. The resulting synthesis, that of Freebop, was never a clearly defined school. The best examples are to be found in the recordings of Joe Henderson and Andrew Hill on Blue Note from the mid-1960s and in some aspects of Miles Davis' work from the same period. However, for much of the 1960s, Free and Bebop developed in parallel with little sign of clear synthesis, although some musicians switched from one school to the other-e.g., John Coltrane (1926-1967). Likewise it is not completely satisfactory to posit Post-Bop (e.g., the Marsalis brothers) as antithesis to Fusion, since the Fusion movement had already largely vanished by the time Post-Bop became prominent in the carly-1980s. M-Base, like Frecbop, has never had many adherents (examples include Steve Coleman in the USA and Steve Williamson in Europe, but there are few others). The No Wave movement of the late-1970s (e.g., James Blood Ulmer and Ronald Shannon Jackson), much influenced by Punk Rock, was arguably a more important school than M-Base, but developed before Post-Bop and therefore cannot be regarded as a legitimate synthesis, but rather as the final stage of Fusion before its collapse.

Additionally, although dialectic transitions (a) and (b) account for Benzon's transitions to Ranks 2 and 3, there is little indication of how the two alternative traditions, those of Rock/ Soul and Hiphop/Rap (this latter is regarded here as Rank 4-although not by Benzon, 1997) fit into the system. One might adopt the well-known position of Rahsaan Roland Kirk (1936- 
1977) that jazz is "Black classical music" (Berendt, 1983, p. 253), and that the other traditions, along with their Blues and Gospel roots, are merely "folk." However, this is less tenable now than it was in the 1960s, since much of Rock/Soul is highly compositional and has clearly reached at least an advanced Rank 2 status. Rap/Hiphop, if it is to be considered as Rank 4, appears to have reached that level without the benefit of intermediate Rank 2 and 3 stages, consisting as it does of complex collages of recorded sound prepared in an improvisational manner in a studio without any requirement for musical "literacy" as traditionally conceived.

Dialectics, in its later Marxist form, also requires that the process of cultural change be linked to economic progression. African-American society does not easily lend itself to Marxist analysis since, in addition to the class differences within that society, there is also the relation of African-American society as a whole to the White society in which it is embedded. The first synthesis, that of Swing in the 1930s, can be scen as parallel to the emergence of the African-American industrial proletariat in the cities of the American North. The second major synthesis, that of Bebop is simultaneous to the emergence of the educated middle classes. Further parallels are difficult to derive. It is arguable that the set of antitheses-Jump in the 1930s, Free in the 1950s, and Rock/Soul in the 1960s-represent grass-roots movements pulling against the prevailing tendency to complexity and deriving their inspiration from folk sources, such as Blues and Gospel, closer to Africa than White America.

Although a dialectical system seems to conform reasonably well to the standard history of African-American music, there are clearly some discrepancies, and the reader will be able to attack the above outline even further. Whether these can amount to falsification of dialectics is unclear. As Popper (1945, 1957, 1959/1972) has pointed out, dialectics may generally always be saved by its proponents simply by adjusting which facts one chooses to submit to the analysis, or by allowing ad hoc adjustments to the theory. It is a meta-narrative rather than a scientific theory. Those who are convinced of the validity of dialectics (such as Marxists) will not allow discrepancies, small or otherwise, to deflect them. Nevertheless, even if no ideological stance is taken, it is clear that dialectics, although not perfect in the present context, does throw up some interesting patterns. The question which must now be addressed is whether the Darwinian approach of memetics can be informative where dialectics proves wanting.

\section{A Darwinian Approach}

Just as the gene pool of African-America is derived from both European and African sources (reviewed by Cavalli-Sforza \& Bodmer, 1971), so is its meme pool neither strictly African nor European, but a mixture of both with the component parts under selection. The greatest problem that presents itself is, as Benzon (1996) has pointed out, the exact identification of those selective forces. One suggestion that Benzon makes is that internal conceptual coherence is an important factor. In other words, new memes must fit easily into the pre-existing meme pool, and be able to function in the context of memes already in use. A more Dawkinsian approach might involve an analysis of the effectiveness with which memes are transmitted. A third possibility is the interaction between memes and physical realities, such as economic change and availability of technology.

The rate of change in all 20th century culture means that an individual inhabits several cultural environments in one lifetime. A 70-year old person of the present day was born into 
a world where Louis Armstrong (1900-1971) still represented the most advanced developments in jazz and the Second Viennese School was just beginning to make an impact in European classical music circles. That person reached maturity well before the arrival of Free in the late 1950s, and was already middle-aged by the time Fusion emerged in the 1970s. Of course, many individuals do manage to cope with, and make a contribution to, several different cultural environments-for instance Miles Davis (1926-1991)-but the majority of individuals are often culturally bewildered by the time they are in their mid-thirties. This helps to explain the repeated tendency for revivalist movements in 20 th century populat music: for example, the survival of New Orleans jazz, and some increasingly ersatz derivatives, in Britain throughout the 1950s and $1960 \mathrm{~s},{ }^{11}$ and the present wave of Adult-Oriented Rock (AOR). These movements often seem to have deliberately stopped the process of cultural evolution. This fits Benzon's conception of cultural coherence. Once an individual has acquired a self-sufficient cultural personality, the receptivity to new memes appears to ccase. A younger individual is not necessarily more "open-minded"-it is rather merely the case that there is a "cultural niche" to be filled in that individual's mind. Some individuals may continue to seek out new memes throughout their lifespan, but for the majority it almost appears that there is a memetic equivalent of "immunity" operating. To this extent, the prevalence of memes seems to depend largely on the frequency of individuals that carry them, paralleling Kuhn's ideas on the death of paradigms (Kuhn, 1962/1970). ${ }^{12}$

Applying this principle to the evolution of African-American music, one might speculate that distinct schools of jazz represent coherent schemes, or musical paradigms. Evolution is possible within these paradigms, providing the underlying form of the paradigm is not affected. For instance, the paradigm of "Behop and directly derived styles" encompasses a lineage from Charlie Parker (1920-1955) to Wynton Marsalis. The music of these two artists may sound quite different if played consecutively, but a conceptual coherence is evident. The paradigm has not been infringed. A thought experiment in which a Bebop enthusiast from the 1940s was transported directly to the present day, would result in that individual recognizing Marsalis' music as belonging to the same tradition, but probably finding Hiphop incomprehensible. Similarly a Heavy Metal paradigm can be identified, even though Steppenwolf and Metallica would sound very different when played consecutively. ${ }^{13}$

Benzon's principle of conceptual coherence helps to explain the existence of gradually evolving schools of music over several decades. New memes, such as novel chord patterns, rhythmic changes, or alterations in instrumentation are subject to scrutiny as to how they cohere with the pre-existing whole. Sudden innovation is not permitted but small innovations may cumulatively have large results. In the example of the Bebop paradigm, one may see gradual changes in the style of bass playing-from Oscar Pettiford's (1922-1960) and Ray Brown's smooth "walking bass" through Ron Carter's crisper and more syncopated sound to the virtuoso pyrotechnics of today's bass players. Nevertheless, the Bebop paradigm of acoustic bass in a support role is maintained. It is not permissible for the bass player to pick up an electric bass and play power chords. That would violate the paradigm. Likewise a modern Bebop pianist has considerably more harmonic freedom than Bud Powell (1924-1966) or Al Haig (1924-1982) ever did, but this does not extend to permission to play Cecil Taylorstyle note clusters or to revert to boogie-woogie left hand (unless some intentional parody is involved).

Paradigm shifts ("revolutions" in Kuhn's terminology) are more difficult to explain, requiring as they do more wholesale memetic change. Here the principle of conceptual coher- 
ence seems to go into reverse with innovation becoming selectively advantageous, at least temporarily. Two situations in which this may occur are (i) when internal pressure builds up within a tightly defined paradigm and younger musicians, whose internal cultural "space" is not yet filled, lose patience with the older, or (ii) when a paradigm is suddenly exposed to a completely different set of memes and an unavoidable mixing takes place. Examples of the first kind may include the development of Bebop out of Swing. Several musicians in diverse localities seem to have been increasingly impatient with the Swing paradigm as it had developed by the late 1930s. When they found themselves together in New York, this resulted in the rapid evolution of a new style free from the old paradigm's regulations of taste. The most obvious example of the second kind is the emergence of Fusion in the 1970s when Bebop and Free musicians were confronted with the media onslaught of Rock and Soul, and adoption of the new memes appeared irresistible.

Moving on from Benzon's theory to Dawkins' original formulation of "selfish" memes, one might ask how the various components of African-American music were able to "colonize" so many minds. Roswell Rudd (quoted by Berendt, 1983, p. 219) has hypothesized that Blues has a strong affinity with many other world folk musics, thus giving it universal appeal. It is certainly difficult to identify any musical memes that seem to be selfish. One of Dawkins' (1976) examples concerns his own inability to stop hearing the opening bars of Beethoven's 5th Symphony in his head after they had been repeatedly played by a radio news program. Such "catchiness" is displayed as an example of memetic selfishness. This may not be very satisfying, but the converse situation is more easily analysed. For instance, there is a limit to the complexity of musical phrases that can be memorized. Many people can sing back a Bix Beiderbecke (1903-1931) solo, note for note, but few could do the same with any John Coltrane (1926-1967) solo. One may be greatly transported by a Free performance, but little specific detail may remain in the mind a few days later. This apparent difficulty in transmissibility also occurs in much 20th-century European classical music. Individuals may whistle Mozart on the bus but few whistle Stockhausen. Extreme complexity is evidently memetically maladaptive. For this reason, Minimalism was the obvious reaction to the Darmstadt school. Any paradigm which becomes so complex that it loses any simple transmissible component will not enter minds efficiently. The resulting empty cultural niche will be available for colonization by more efficiently transmitted memes. This fate has successively befallen Bebop in the 1960s, Progressive Rock in the 1970s, and is beginning to happen to contemporary electronic dance music. ${ }^{14}$

Recently, Zentner and Kagan (1996) have raised the intriguing possibility that humans have an inherent aversion to dissonant music. This study was based on the reactions of 4month old babics to consonant and dissonant melodies and chord sequences. If Zentner and Kagan's results are borne out by further research, then this may represent a basic selective force against the development of harmonic dissonance. Harmonic complexity inevitably brings together dissonant combinations of notes, and there may therefore be biological limits to what is culturally acceptable in harmony. ${ }^{15}$

The third and final selective scenario is interaction of musical memes with material forces not directly connected with music. It is obvious in the history of African-American music that styles have been connected with certain localities. From Chicago and New Orleans jazz in the 1920s to the Philadelphia sound, the Motown sound, and even the Seattle sound of more recent years, musical schools often seem to develop best when there is an element of isolation. Demographic shifts may then give rise to new cultural forms as local styles 
come into contact. The great migration North created Chicago jazz, and 1960s Californian Rock fused many local blues and country styles brought to the West Coast by migrants from the Dust Bowl states. ${ }^{16}$

Interaction may also take place with technological change. For instance, the development of electric instruments gave musicians a whole range of new capabilities, many of which took some decades to be fully explored. ${ }^{17}$ The music industry boom of the $1960 \mathrm{~s}$ resulted in far larger audiences, which demanded higher volumes of live sound. Berendt (1983, p.4\%) has posited the interesting hypothesis that increased volume was one of the principal factors in the switch to a simpler bass-drum-laden style by Rock drummers in the late 1960s. Early Rock drummers were more jazz influenced, ${ }^{18}$ but intricate patterns sounded very messy and indistinct at high volumes. As festival audiences grew and Rock bands became progressively louder, the drum sound had to be simplified in order to be clear. Only with the development of more reliable high volume sound systems in the 1980s could Rock drummers once again fill the spaces between beats with other sounds. A converse process took place in the 1920s when drummers were forced to reduce the bass drum input and concentrate on cymbals in order not to jolt the needle on the wax cylinders used in recording (Berendt, 1983, p. 326). ${ }^{19}$

\section{Is Memetics Scientific?}

The above analysis may seem diffuse when compared with the preceding dialectical approach. This is because memetics does not posit any single mechanism for change, but merely that any kind of selective pressure can operate on memetic variation. Identifying the selective pressure is the greatest challenge (Benzon, 1996). Once a candidate selective force has been identified, one must then seek to examine all the situations in which it might have operated and the ensuing results. Several selective pressures may be operating at once. It is reasonable to conjecture that internal coherence, requirements for effective transmissibility (possibly including biologically inherent aversion to certain sounds) and social/technological/economic factors may all be acting simultaneously. Additionally, dialectics deals with ideas on a grand scale, whereas memetics is by definition reductionist, and must explain small scale changes before it can hope to explain larger ones.

J. B. S. Haldane (1949) proposed a unit for the quantification of evolutionary change. Appropriately enough, he termed it the "darwin," and defined it as a change in the average dimension of a trait by a factor of "e" (2.718) in one million years. The use of the word "average" is important, as a biologist or palaeontologist will always consider the evolution of a species as a whole, and that species will always display variation. The same is true in cultural evolution. When we are examining the evolution of jazz, we must include all jazz currently played, and compare it with, say, all jazz played in 1940. To restrict ourselves to the most avant-garde styles of the eras we are comparing is equivalent to a palaeontologist only examining the most extreme skeletal remains and ignoring the typical. We may, of course, choose to reduce the amount of material to be examined by considering the evolution of a single lineage, such as bebop only, or even more narrowly, the evolution of a single artist over a defined period. The point is that whether we choose a wide or narrow research topic, averages must always be considered. However, the narrower the sample, the less will be the likelihood of discovering any novel general mechanisms of change. 
I propose that the unit of cultural evolution be termed the "tylor," in honor of the great anthropologist Edward Burnett Tylor (1832-1917) (see Mair, 1972, p. 23; Leach, 1982, pp. 38-39), whose pioneering studies of "social arithmetic" were the first approaches to the quantitative analysis of culture. Tylor's reductionist approach has much of the flavor of memetics. One "tylor" is a change in the average dimension of a cultural trait by a factor of " $\mathrm{e}$ " in 100 years. An analysis of evolution in jazz could involve the selection of a database of piano recordings from a series of time points, e. g., 1920, 1940, 1960 and 1980, and the quantification of various traits, e. g., number of notes in a chord, number of different time signatures used, length of a piece, melodic range, dynamic range, etc. Any aspect that can be reasonably quantified can be included. The initial analysis will yield values for rates of change in "millitylors." 20 This demonstrates change, and rate of change. The second stage is to derive hypotheses for the cause of that change, in terms of any of the selective forces posited above. The third stage is to attempt to falsify the hypotheses by means of examination of further pertinent data.

This is the nearest approach to experimental method that can be achieved in a non-laboratory discipline. It is basically the same approach used by molecular evolutionists or bioinformaticists who study the evolution of DNA over geological periods of time. Here musical material has replaced DNA sequences, and geological time has been replaced by decades, but the basic philosophy and approach are the same. Memetics, it seems, can be a science, if only a means of quantifying cultural change and appropriate fields of study can be agreed upon.

This is not enough for some of the more doctrinaire philosophers of science. The Nobel Prize-winning molecular biologist Francis Crick apparently does not regard evolutionary biology as scientific (quoted by Dennett, 1995), principally since a great quantity of abstract entities and deliberate oversimplifications are required. Furthermore, a true experiment in evolution, of the sort that would satisfy a laboratory scientist, can rarely be set up. Analysis is always retrospective, conditions cannot be controlled, and the predictive power of a hypothesis may take years to test, and even then the results may be ambiguous. If evolutionary biology sits on the frontiers of pseudo-science, what hope can there be for an evolutionary analysis of the even more elusive entities of culture?

An even more fundamental objection is provided by the Popperians, who would argue that memetics is not falsifiable, and therefore merely a meta-narrative having no more right to call itself scientific than dialectics (Popper, 1959/1972; Popper, 1974, pp. 118-121, 133143). Since memeticists believe that all natural phenomena, both biological and cultural, display variation, and that this variation is subject to inevitable selection, the Darwinian evolution of culture is inescapable - just as the Darwinian evolution of biology is inescapable-indeed, the Darwinian evolution of any replicator system is inescapable. ${ }^{21}$ This is the principle of Universal Darwinism (Dawkins, 1983). To rigorous Popperians, all theories must provide for certain circumstances in which they would be rendered falsified. It was precisely the reluctance of Freudians in pre-war Vienna to admit of even a hypothetical circumstance for which Freud's ideas might fail to provide an explanation, that led Popper to reject verificationism and postulate falsifiability as an alternative (Popper, 1959/1972). Universal Darwinism is a meta-narrative, since there is no possibility of phenomena that do not exhibit some variation, and there is no possibility that such variability will not be subject to any selective forces existing in the system. In its strongest form, then, Universal Darwinism provides a cogent metaphysical system, but is not scientific in the Popperian sense. 
However, the reality is somewhat different, and more favorable to memetics. Darwinism did not arrive as a fully fledged meta-narrative, but as a highly controversial theory, which suggested all manner of testable hypotheses. Darwinism was also falsifiable as a whole, and indeed Darwin died believing, rather tragically, that it had been falsified by Kelvin's measurements of the age of the Earth (according to Desmond and Moore, 1991). The falsification was invalid, as Kelvin's data was subsequently shown to be incorrect. The present refusal of biologists to admit that Darwinism could ever be falsified is not a piece of meta-narrative arrogance but rather arises because, as Francois Jacob (1982/1989) has pointed out, Darwinism is still a theory but "the chance that this theory as a whole will someday be refuted is now close to zero" (p. 371-Jacob's italics). Darwinism in biology is not, as some creationists would have one believe, a controversial theory. It is a highly tested and virtually impregnable body of evidence. 22

So much is true of Darwinism in biology, but what of culture? If Universal Darwinism is "merely" a meta-narrative then, at best, memetics can be seen as a "metaphysical research programme" (Popper, 1974, pp. 118-121, 133-143; Lakatos 1978) having its internal logic and rules but, being unfalsifiable, no objective validity from a scientific point of view. In order to satisfy the Popperians, we need to design experiments capable of falsifying memetics as a whole-i.e., not just falsifying sub-hypotheses within the unfalsifiable meta-narrative of Universal Darwinism.

There is one such possibility. The fundamental theorem of natural selection requires that selective forces be operating at least some orders of magnitude higher than endogenous rates of change (Williams, 1966). If this criterion is not satisfied, then natural selection cannot operate, as it is subsumed in random variation. In biology, the endogenous rate of change is provided by mutation of DNA, and this is kept to a low level. That is why Darwinian natural selection can operate at the biological level. If the generation of cultural variation is higher than the permissible limit, then natural selection cannot operate in culture and memetics can be considered falsified. This experiment requires two sets of data: (i) a measure of the rate at which a culture generates diversity, i.e., its "mutation" rate, and (ii) a measure of the rate of cultural change over time. More specifically, in the terms of population genetics, we need to examine the change in the abundance of two alleles at a locus in order to calculate selection pressure. Of course there are no obvious "loci" in memetics (although geographic localities as origins of jazz styles might suffice), but mutually exclusive beliefs may be considered as "alleles." One example which might be used in this case is that of religion since, in European cultures at least, one individual generally does not have two religions. The selection pressure could be calculated by the examination of the relative change in number of adherents of each religion considered, and the mutation rate by the rate of appearance of new sects. Given that some sects may arise and expire without even entering the history books, the mutation rate must always be considered the minimum value.

These are perhaps crude and ad hoc measures, but empirical experience in this kind of analysis may suggest more sophisticated tests. It is important that at least some attempt be made to ground memetics on a firmer empirical footing. So far there has been much philosophizing and some attempts at mathematical simulation (Cavalli-Sforza \& Feldman, 1981, Cavalli-Sforza et al., 1982, 1983; Moritz, 1990; Lynch, 1996) but relatively little empirical analysis. Appropriately enough when music is being considered, the most extensive empirical studies of memetics have been carried out in birdsong (Payne et al., 1988; Lynch et al., 1989; I.ynch \& Baker 1993, 1994; Ficken \& Popp, 1995; Baker 1996). These investigators 
recorded the changes in prevalence and distribution of songs over geographical areas and time ranges, identifying several phenomena analogous to those of genetics, such as founder effects, divergence within lineages, and linkage groups. However, in general, birdsong memes appear to be selectively neutral, giving no clues to the selective pressures, if any, involved in avian "culture."

The best empirical memetics paper in humans is by Guglielmino et al (1995), and this tends to suggest that many human memes may also be selectively neutral. These investigators analysed 47 cultural traits in 6 broad groups, across 277 African societies. Three hypotheses were entertained: (a) that culture is mostly transmitted within families ("vertically"), in which case traits will be concordant with linguistic groups (language being an excellent example of a vertically transmitted trait in most circumstances); (b) that culture is an adaptation to the local environment, in which case traits are concordant with features of local geography and climate; and (c) that they are transmitted to ncarest ncighbors ("horizontally"), in which case traits would appear in geographic clusters independent of linguistic group and local environment. The data was found mostly to conform to the model (a), with model (c) being the least supported. The possible interpretations of this data in terms of selective forces and the degree of cultural isolation of the cultures concerned are too complex to deal with in the present paper. However, the way may be pointed to a more truly empirical human memetics.

We should not be overzealous in dismissing memetics should it fail its initial empirical tests. As Feyerabend (1963/1968) argued, a new paradigm needs some time to breathe and fortify itself theoretically before entering into the heat of critical debate. Literal interpretations of new theoretical postulates can almost always be falsified, as new theories inevitably contain some conceptual flaws, of varying degrees of severity. Some gentle empirical testing will allow memetics to shed some of its theoretical fat and develop the strength needed to survive the more rigorous tests to come. And come they must.

\section{Predicting the Future of Jazz}

There will presumably always be African-American music of some variety. Jazz, however, has been declared dead on several occasions, but has never quite expired. If memetics is scientific, one ought to be able to make some predictions concerning the future of jazz in the overall spectrum of African-American music. The dialectic approach suggests that the inherent tension between African roots and cosmopolitan environment will cause further syntheses to emerge. However, there is scarcely sufficient musical consensus in the jazz world in the late 1990 s to permit even a guess at what the predominant thesis might be. Post-Bop and MBase are poor candidates. The unanimity of the $1950 \mathrm{~s}$ has disappeared, apparently for good. Without a strong thesis, there can be no antithesis and the dialectical process will terminate. Contrary to Hegelian predictions, the "Geist" has dissipated rather than continued its upward self-realization.

Through memetic spectacles, we may see the meme pool of the jazz world fusing with the general meme pool of global culture. Assimilation may bring a bland diffuseness to the music, as jazz feeling is submerged in a dozen other styles of diverse ethnic backgroundscountry, latino, rock, techno, rap, etc. However, it should be remembered that memes, like their genetic analogues, can behave in a particulate manner. Fragments of material may survive intact for surprising lengths of time, resurfacing in the most unexpected places. Memetic 
recombination may even serve to regenerate some of the diluted descendants of jazz memes. The music of the year 2097 may sound strange to our ears, but the resilient remnants of swing, blues (meaning the real blues), and bebop may be buried deep. A distant echo of "Donna Lee" might, on rare occasions, cut through the cybertonal haze, and Charlie Parker, wherever he is, may manage the ghost of a smile.

\section{Notes}

1. Even within the Western sphere there are relatively static musical styles. For instance, Gregorian chant has survived in monastic isolation, little altered since the 8th century C.E.

2. The question of complexity and progress in biological evolution has been hotly debated. Stephen Jay Gould (1989) has argued strongly against the idea that evolution exhibits any progressive tendencies, on the grounds that this implies some kind of spurious goal-directedness. Such a grand teleological notion of evolutionary progress has been given a religious inflection by those wishing to reconcile Darwinism with Christianity (e.g., Teilhard de Chardin, 1959), who are among Gould's principal targets. On the purely scientific level, R. A. Fisher's Fundamental Theorem of Natural Selection (Fisher, 1930) demonstrates that there must be an increase in the mean fitness of an evolving population, which may be taken as evidence of progress of a sort. However, Maynard Smith and Szathmary (1995) point out that Fisher makes an invalid assumption concerning the relative fitnesses of different genotypes over time. Nevertheless, they concede that: "Even if progress is not a universal law of evolution, common sense does suggest that at least some lineages have become more complex" (Maynard Smith \& Szathmary, 1995, p. 5). The same sentiments are equally applicable to cultural evolution.

3. Even at this early stage in its development, memetics is already showing signs of an ideological split. Much of the debate is conducted over the Internet (in private "lists") and therefore not fully in the public domain. Broadly, one camp, following Dawkins' lead, emphasizes the "selfish" nature of many memes (e.g., Dawkins, 1993; Lynch, 1996), and has coined the phrases "thought contagion" and "mind viruses." These are mostly used in the context of attacks on religion, sexual taboos, and other memes which these authors regard as parasitic. A flavor of the tone of the debate can be given by a quotation from Dawkins (1993): "Is science a virus? No. Not unless all computer programs are viruses. Good, useful programs spread because people evaluate them, recommend them and pass them on. Computer viruses spread solely because they embody the coded instructions: 'Spread me'." The possibility that religions are also, in some contexts, good and useful, does not seem to be considered. Dawkins and his followers wield memetics as a rhetorical weapon against "nuns, Moonies and their ilk" who are simply "potent infective agents" for "a mutually supporting gang of viruses" (Dawkins, 1993). The alternative approach is to take a value-free stance which considers memes simply as the abstract units of a reductionist approach to cultural evolution (e.g., Gatherer, 1997 a,b,c). In this view, religion, science, music, and any other aspects of thought are examined on their own terms, as evolving systems of culture.

4. Scruton (1995) gives a comprehensible exposition of Hegel (pp. 161-175), and also points out (p. 217) that the phrase "dialectical materialism" was coined by G. V. Plekhanov, and is not Marx's. Although Marx developed his philosophy from that of Hegel, he placed less emphasis on dialectics than his followers subsequently did.

5. One of the most prominent non-Soviet theorists who insisted on the scientific status of Marxism was Louis Althusser (1977, p.7): that "this science cannot be a science like any other.... is unbearable for the bourgeoisie and its allies." It is certainly unbearable for Popperians.

6. Defining "jazz" has never been easy (for instance, see Berendt, 1983, pp. 449-457). The term "African-American music" is occasionally used here rather interchangeably with "jazz," as I am willing to accept the broad definition that jazz is any music primarily of African-American derivation containing a least some improvisational features in performance. This would include jazz performed by European musicians, and also improvisational styles of Rock and Blues. It excludes African popular dance music 
such as Highlife, Juju, and Kwela; non-improvisational Rock; and also improvised music not of AfricanAmerican derivation, e.g., the followers of John Cage (1912-1992). Defining "modern jazz" is far easier, as this can be seen as any music descended from bebop, or containing bebop clements. This conveniently excludes Rock, Blues, and New Orleans revivalists, while allowing most of the better quality Fusion music. However, it may admit some Funk, since Horace Silver was a strong influence on James Brown, and Bop lines can occasionally be distantly detected in Funk riffs.

7. African-American musicians had been attending musical conservatories intermittently since the middle of the 19th century, and many would have been musically literate. However, these musicians were part of the European tradition, whatever their ethnic background. Additionally, Ragtime composers such as Scott Joplin (1868-1917) had been publishing their music for some 20 years prior to Jelly Roll Morton (Joplin's famous "Maple Leaf Rag" dates from 1897), although Ragtime is not always classified as jazz. Joplin's ambitions were clearly classical, and his opera "Treemonisha," composed in 1911, but not premiered until 1971, demonstrates that he was quite capable of Rank 2 forms, and had designs on Rank 3. Identifying Morton as the first jazz "composer" is also complicated by the fact that many popular songs of the day rapidly became jazz standards, e.g., "Ain't Dat a Shame" composed by Walter Wilson and John Queen in 1901 (not be confused with Fats Domino's early rock 'n' roll hit, "Ain't That a Shame," in 1955), and "Bill Bailey," by Hughie Cannon in 1902. These tunes are so familiar in traditional jazz arrangements that it is hard to imagine them played in any other manner. Although it is obvious that jazz evolved rather than was invented, Morton may in fact have been the first to realize that a new musical form, neither Spiritual nor Ragtime nor European nor Vaudeville, had appeared, and to react accordingly. Morton may not have invented jazz, but he may have "invented" the jazz musician as an artistic entity.

8. It is arguable that African-American music was already comparably sophisticated to the harmonic level of European music, even before the harmonic experimentation of bebop. The use of blue notes, i.e., flattened and raised pitches, gave African-American vocal and wind music a greater melodic flexibility than that of the European diatonic scale. The introduction of keyboard instruments, which are not capable of producing blue notes, may have shifted jazz harmony towards the European model, and simplified it in the process. Alan Lomax (1993) advances the interesting hypothesis that the blues scale is a relatively recent development, indigenous to the Mississippi Delta region, and appeared as an emotional response to social conditions around 1900. Lomax claims that earlier forms including work-songs and spirituals do not use the blues scale but wide-ranging intervals, similar to those of African music. The first blues recording was "Memphis Blues" composed by W. C. Handy (1873-1958) and performed by the Charles Prince Orchestra in New York City on July 24, 1914 (Vail, 1993).

9. Benzon's theory of Ranks is designed to apply to culture as a whole and not just to music (Benzon \& Hays 1990; Benzon, 1993; Benzon 1996, 1997). Rank 3 is regarded as the level at which "Art" as a self-conscious process emerges, as opposed to the basic emotional expression of Rank 1, and the entertainment function of Rank 2. I would differ with Benzon in that I regard Hiphop as a Rank 4 phenomenon.

10. In the majority of these cases, the thesis-antithesis polarity is between the European and African elements in the music. For example, New Orleans, Jump, Free, and Rock (that of Jimi Hendrix, 1942-1970, rather than the Beatles) sit on the African side, with their emphasis on direct expressive force. Chicago, Swing, Hard Bop, and Fusion have a high content of self-conscious intellectualization. A Hegelian might posit that the inherent contradiction (all ideas contain their contradictions, according to Hegel) in African-American music is the inevitable tension between African and European roots. These elements are seen as incompatible but inseparable. This continual shearing force will tear apart any attempt at long-term synthesis, thus ensuring a rapid evolution. Rock music, in Britain at least, appears to suffer from a comparable tension between intellectualizing and emotional elements. In this case, the contradiction is less between African and European as between middle-class and proletariat. The middle-class intellectualizing tendency produced Progressive Rock (e.g., Pink Floyd, Tangerine Dream) in the 1960s and Acid House/Rave/Techno (e.g., Soul 2 Soul, The Orb) in the 1980s, both of 
which emphasized technical sophistication, instrumental experimentation, extended improvisation in performance and increasingly large-scale composition. Opposition has been provided by Punk (e.g., The Sex Pistols, The Stranglers) in the 1970s and Britpop in the 1980s (e.g., Blur, Oasis), with their emphasis on "traditional" guitar-group instrumentation, and short, direct, and often angry songs. However, the dialectic in Rock has not produced any convincing syntheses--the supremacy being passed from the intellectual to the visceral and back again in decade-long cycles. One might speculate that this is because there are really two musics here and that a permanent split has already occurred. European popular music may gradually shed its non-European influences, but African-American music is permanently hybrid and so the dialectic must continue (although, as pointed out in the final section of main body of the present article, there is little evidence of any dialectic process in action at the present time).

11. The post-war New Orleans revival in the UK created a climate in which all kinds of American music were avidly discussed and consumed. This climate created The Rolling Stones and The Beatles, who recycled the British interpretation back into American music.

12. Thomas Kuhn's (1962/1970) ideas on "paradigms" are equally applicable to other fields. In jazz, the implication is that a style may die away only when most of those involved in its initial formulation are dead. It then becomes a subject for historical interest and debates concerning authenticity of style, rather than a living and evolving music. Almost all of the pioneers of New Orleans jazz are dead, and most of the original Bebop generation, with a handful of exceptions. There are as yet few debates concerning authenticity in Bebop, but they will become increasingly important to a diminishing band of enthusiasts, as they already are for New Orleans and Country Blues performers, who have no direct personal contact with the founders of their styles. Likewise, the deaths of the majority of the 60s Rock generation by the year 2020 may finally cut the ties with the 20th century and Rock will acquire the same quaint irrelevance possessed by Dixieland jazz today. European classical music became increasingly involved in its own past in the early 19th century. Until then the majority of performances had been of contemporary works, often poorly rehearsed and ill-received by boisterous audiences. The rediscovery of the works of J. S. Bach and the realization that European music had a deep and rich history, coupled perhaps with the rejection of the avant-gardism of the Late Romantics, turned European concert music into an increasingly sedate and respectful contemplation of "classics." Today, few orchestras are willing or able to attempt new compositions.

13. Steppenwolf's "Born to Be Wild" (1968) is often cited as the first Heavy Metal record, but the roots are evident in much 60s Blues-Rock guitar music (e.g., The Yardbirds, Cream). A Django Reinhardt (1910-1953) recording from around 1947 entitled "Blues en D mineur" contains a passage in which Reinhardt suddenly delivers a series of rhythmic power chords, briefly creating an effect at least 20 years ahead of its time.

14. European classical music appears to develop in much slower cycles in which complexity increases to the point where the audience, and many of the musicians, can no longer comprehend the music. The consequent process of rejection leads to a vacuum where a simpler musical style can enter. The first cycle of this kind began with Gregorian chant, which developed through organon and early polyphony to the Ars Nova of the early 14th century. This polymodal style (typified by the complex compositions of Guillaume de Machaut) gave way to a simpler style as the diatonic key system was established. The second cycle developed into the polyphonic complexity of Late Baroque, which then collapsed and was replaced by the simpler monophonic sound of Early Classicism. Just as the end of the Mediaeval era had been heralded by the introduction of diatonic scales, the end of the Baroque era was consequent on the even-tempering of keyboards. Classicism developed through Romanticism and Serialism to the Darmstadt School. This cycle collapsed by the mid-1960s and has been succeeded by Minimalism. The transition between cycles is always acrimonious. Late Baroque composers such as Handel heaped the same kind of abuse on their "simplistic" successors such as Gluck, as the last of the 20th century's complex avant-gardists reserve for the likes of Philip Glass. Gluck and his contemporary C. P. E. Bach are regarded as musicologically important but unimpressive as artists. However, they were soon succeeded by the genius of the Viennese composers (Haydn, Mozart, Schubert, and Beethoven). What- 
ever one thinks of contemporary Minimalism, if classical music follows a similar cycle yet again, a golden age is in store. It is also perhaps worth noting at this point that schools of classical music are frequently given the same names as schools of painting. Just as there are Romantic, Impressionist, Expressionist, and Minimalist painters, so there are the identifiable composers of the same type. Music always seems to lag behind the visual arts in this respect. The Impressionist composers (e.g., Debussy, Ravel, etc.) followed the Impressionist painters by some 30 years or more. Likewise, Minimalism in painting was already over by the time the corresponding musical school appeared. Whether this indicates that visual arts are the driving force of Western culture and music follows tardily behind, or whether it is due to the lower cultural profile of composers relative to painters, is worth debating. As far as I know, nobody has done so, possibly because art critics are rarely interested in music.

15. Some of the harmony of the Total Serialist era of Western classical music (from around 1945 to 1960, typical composers include Pierre Boulez, Luigi Dallapiccola, 1904-1975, etc.) is by definition as dissonant as can be achieved within the 12-semitone-octave system, in that some chords may contain all 12 tones. The most dissonant music in jazz is probably that of Cecil Taylor, whose piano performances include the use of the forearm applied to the keyboard to include clusters of several octaves. Both the Total Serialists and Taylor are also capable of great lyricism, all the more striking for the agonized music in which it is embedded. Making more discordant music would require the insertion of quarter-tones. This was achieved by Charles Ives (1874-1954), whose 4th Symphony, composed around 1916-1920, calls for two pianos tuned a quarter tone apart. A more regular use of quarter tones is found in the work of Alois Haba (1893-1972), a Czech composer inspired by his native, non-diatonic folk music. Haba was much talked about at one time but little played. Atonality evolved independently on at least three occasions: in the work of the Second Viennese School (2nd String Quattet, 1908, by Anold Schoenberg, 1874-1954), in Russia ("Two Compositions for Piano," 1915, by Nikolai Rosslavets, 18801944) and in the USA ("The Banshee," 1914, by Henry Cowell, 1897 1965). Whether the exiled Edgard Varese (1883-1965) developed atonality (in his "Ameriques," 1921) independently of the Second Viennese School is debatable (Griffiths, 1994; Rich 1995). To these three, possibly four instances, we might add a fifth, that of Ornette Coleman. Just as the eye evolved independently in insects, vertebrates and molluses, so may the same cultural features arise in divergent lineages.

16. Many of the Californian musicians of the late $60 \mathrm{~s}$ were born in areas where they were exposed to city or rural Blues styles. Among the better known migrants were Janis Joplin (1943-1970, Port Arthur, Texas), Grace Slick (Chicago), Ray Manzarek (Chicago), and Charles Lloyd (Memphis, Tennessee).

17. The pioneers of the electric guitar such as Charlie Christian (1916-1942) and Les Paul, were presumably aware of the possibilities of the instrument but used it in only limited ways (e.g., Paul's "How High the Moon," 1951) compared to what was to come. This is an example of Benzon's conceptual coherence as a selective constraint.

18. Examples include Ginger Baker, John Densmore, Mitch Mitchell, and Keith Moon (19471978), who at his exuherant hest was reminiscent of Buddy Rich (1917-1987). The careers of all of these drummers declined as Rock rhythm became less flexible in the 1970s.

19. In a BBC TV interview of the 1980 s, Rudy van Gelder described how his clear recording of the cymbals on Blue Note records, from the early $1950 \mathrm{~s}$ onwards, stimulated drummers to pay more attention to the intricate and precise use of cymbals, which became a principal element in the Hard Bop sound.

20. As a crude example, it might be speculated that the average number of tones in a chord in a composition by Mozart is 3.5, not counting octave doublings, since many chords will have three tones and some four. In a composition by Webern, the corresponding figure may be 8 . This is approximately an increase of $0.84 \mathrm{e}$ over approximately 150 years, thus giving an evolutionary rate of about 0.56 tylors in the direction of harmonic complexity. One might perform a similar analysis of Scott Joplin rags versus the compositions of Keith Jarrett. Quantifying rhythmic complexity is a greater challenge. 
21. Here Darwinian evolution is taken in the sense of gradual, directional evolutionary change powered by steady natural selection. Other evolutionary phenomena such as neutral drift, saltation, and diversifying selection are also pernitted. Although these are nut strictly Darwinian, most Darwinists would accept at least some role for them.

22. In fairness to Freud, subject of much Popperian condemnation, his scientific training was of the highest order, and his approach to his subjects as scientific as circumstances allowed. He never lost touch with his positivistic roots (Miller, 1962/1991, pp. 249-267). Freud wanted to be scientific; if he failed it was largely as a consequence of the difficulty of couching his findings in a language acceptable to the scientific tradition from which he sprung. The worst bogeyman of the Popperians, Karl Marx, is possibly more guilty of meta-narrative, but unlike Darwin and Freud, he had no scientific training and was laboring under the immense metaphysical weight of Ilegel's dialectics, a system that seemed as sclfevidently true then as Universal Darwinism seems today.

\section{References}

Althusser, L. (1977) Lenin and Philosophy, and Other Essays, Brewster, B., trans. London: New Left Books.

Benzon, W. L. (1993) "Stages in the Evolution of Music." Journal of Social and Evolutionary Systems, 16, 273-296.

Benzon, W. L. (1996) "Culture as an Evolutionary Arena." Journal of Social and Evolutionary Systems, $19,321-362$.

Benzon, W. L. (1997) "Music Making History: Africa Meets Europe in the United States of the Blues," in Ba'Nikongo, N., ed., Leading Essays in Afro-American Studies (in press). Http://www.newsavanna.com/wlb/USBlue/USB2/default.shtml

Benzon, W. L. \& Hays, D. G. (1990) "The Evolution of Cognition." Journal of Social and Biological Structures, 13, 297-320.

Berendt, J.E. (1983) The Jazz Book; From New Orleans to Jazz Rock and Beyond. Bredigkeit, H., Bredigkeit, B. \& Morgenstern, D., trans. London: Grafton Books.

Cavalli-Sforza, L. L. (1986) "Cultural Evolution." American Zoologist, 26, 845-855.

Cavalli-Sforza, L. L. \& Bodmer, W. F. (1971) The Genetics of Human Populations. San Francisco, CA: Freeman.

Cavalli-Sforza, L. L. \& Feldman, M. W. (1981) Cultural Transmission and Evolution: A Quantitative Approach. Monographs in Population Biology, I6. Princeton, NJ: Princeton University Press.

Cavalli-Sforza, L. L., Feldman, M. W., Chen, K. H. \& Dornbusch, S. M. (1982) "Theory and Observation in Cultural Transmission." Science, 218, 19-27.

Cavalli-Sforza, L., Feldman, M., Dornbusch, S. \& Chen, K. H. (1983) "Anthropology and Cultural Transmission." Nature, 304, 1-24.

Dawkins, R. (1976) The Selfish Gene. Oxford: Oxford University Press.

Dawkins, R. (1983) "Universal Darwinism," in Bendall, D. S., ed. Evolution from Molecules to Men. Cambridge, UK: Cambridge University Press.

Dawkins, R. (1993) "Viruses of the Mind," in Dahlbom, B., ed. Dennett and his Critics. Oxford: Blackwell.

Dennett, D. C. (1995) Darwin's Dangerous Idea: Evolution and the Meanings of Life. London: Penguin Books.

Desmond, A. \& Moore, J. (1991) Darwin. London: Michael Joseph.

Dobzhansky, T. (1961) Mankind Evolving. New York: Bantam Books.

Feyerabend, P.K. (1963/1968) "How to be a Good Empiricist - a Plea for Tolerance in Matters Epistemological," in Nidditch, P. H., ed. The Philosophy of Science. Oxford, UK: Oxford University Press. 
Ficken, M. S. \& Popp, J. W. (1995) "Long-Term Persistence of a Culturally Transmitted Vocalization of the Black-Capped Chickadee." Animal Behaviour, 50, 683-693.

Fisher, R. A. (1930) The Genetical Theory of Natural Selection. Oxford, UK: Clarendon.

Gatherer, D. (1997a) "Macromemetics: Towards a Framework for the Re-unification of Philosophy." online Journal of Memetics, 1 , http:// www.cpm.mmu.ac.uk/jom/emit/.

Gatherer, D. (1997b) "Feyerabend, Dawkins and the Politics of Cultural Diversity." Anarchist Studies, 5, 23-43.

Gatherer, D. (1997c) "Meme Pools, World 3 and Averroes' Vision of Immortality." Zygon, in press.

Gould, S. J. (1989) Wonderful Life: The Burgess Shale and the Nature of History. New York: Norton.

Griffiths, P. (1994) Modern Music: A Concise History, rev. ed. London: Thames and Hudson.

Guglielmino, C. R., Viganotti, C., Hewlett, B. \& Cavalli-Sforza, L. L. (1995) "Cultural Variation in Africa-Role of Mechanisms of Transmission and Adaptation." Proceedings of the National Academy of Sciences, 92, 7585-7589.

Haldane, J. B. S. (1949) "Suggestions as to the Quantitative Measurement of Rates of Evolution." Evolution, 3, 51-56.

Hardy, P. \& Laing, D. (1990) The Faber Companion to 20th-Century Popular Music. London: Faber \& Faber.

Jacob, F. (1982/1989) The Logic of Life: a History of Heredity, and, The Possible and the Actual. London: Penguin Books.

Kuhn, T. S. (1962/1970) The Structure of Scientific Revolutions, 2nd ed. Chicago, IL: The University of Chicago Press.

Lakatos, I. (1978) The Methodology of Scientific Research Programmes. Philosophical Papers Vol. I. Worrall, J. \& Currie, G., eds. Cambridge, UK: Cambridge University Press.

Larkin, C. (1992) The Guinness Who's Who of Jazz. Enfield, UK: Guinness Publishing Ltd.

Leach, E. (1982) Social Anthropology. Glasgow, UK: Fontana Press.

Lomax, A. (1993) The Land Where the Blues Began. London: Methuen.

Lynch, A. (1996) Thought Contagion. New York: Basic Books.

Lynch, A. \& Baker, A. J. (1993) "A Population Memetics Approach to Cultural Evolution in Chaffinch Song-Meme Diversity Within Populations." American Naturalist, 141, 597-620.

Lynch, A. \& Baker, A. J. (1994) "A Population Memetics Approach to Cultural Evolution in Chaffinch Song-Differentiation Among Populations." Evolution, 48, 351-359.

Lynch, A., Plunkett, G. M., Baker, A. J. \& Jenkins, P. F. (1989) "A Model of Cultural Evolution of Chaffinch Song Derived with the Meme Concept." American Naturalist, 133, 634-653.

Mair, L. (1972) An Introduction to Social Anthropology, 2nd ed. Oxford, UK: Oxford University Press. Maynard Smith, J. \& Szathmary, E. (1995) The Major Transitions in Evolution. Oxford, UK: W.H. Freeman and Co.

Medawar, P. (1959) "The Future of Man." BBC Reith Lectures 1959 No. 6. Reprinted in Medawar, P. (1990) The Threat and the Glory. Oxford, UK: Oxford University Press.

Miller, G. A. (1962/1991) Psychology: the Science of Mental Life. London: Penguin Books.

Moritz, E. (1990) "Memetic Science: 1-General Introduction." Journal of Ideas, 1, 3-23.

Payne, R. B., Payne, L. L. \& Doehlert, S. M. (1988) "Biological and Cultural Success of Song Memes in Indigo Buntings." Ecology, 69, 104-117.

Popper, K. R. (1945) The Open Society and its Enemies. Vol. II: The High Tide of Prophecy: Hegel, Marx and the Aftermath. London: Routledge.

Popper, K. R. (1957) The Poverty of Histuricism. London: Routledge and Kegan Paul.

Popper, K. R. (1959/1972) The Logic of Scientific Discovery, 3rd ed. London: Hutchinson and Co.

Popper, K. R. (1974) "Intellectual Autobiography," in Schlipp, P. A., ed. The Philosophy of Karl Popper, Vol. I. La Salle, IL: Open Court.

Rich, A. (1995) American Pioneers: Ives to Cage and Beyond. London: Phaidon Press Ltd. 
Scruton, R. (1995) A Short History of Modern Philosophy: From Descartes to Wittgenstein, 2nd ed. London: Routledge.

Teilhard de Chardin, P. (1959) The Phenomenon of Man. New York: Harper Brothers.

Vail, K. (1993) Jazz Milestones: A Pictorial Chronicle of Jazz 1900-1990. Chessington, UK: Castle Communications.

White, L. A. (1959) "The Concept of Culture." American Anthropologist, 61, 227-251. Reprinted in Montagu, A. (1962) Culture and the Evolution of Man. New York: Oxford University Press.

Williams, G. C. (1966) Adaptation and Natural Selection. Princeton, NJ: Princeton University Press.

Zentner, M. R. \& Kagan, J. (1996) "Perception of Music by Infants." Nature, 383, 2-9.

\title{
Acknowledgments
}

Biographical details of musicians are derived from Hardy and Laing (1990) and Larkin (1992). The author thanks Dr. David J. Sutherland (Harvard University) for numerous enlightening conversations on jazz techniques and performers.

\begin{abstract}
About the Author
Derek Gatherer, Ph.D., currently lectures in the School of Biomolecular Sciences at Liverpool John Moores University, and pursues research interests in the molecular evolution of DNA sequences and cultural evolution using the gene/meme analogy. Previous articles in a similar vein can be found in the online Journal of Memetics (http://www.cpm.mmu.ac.uk/ jom/emit/) and Anarchist Studies, vol. 5. An article in Zygon: Journal of Religion and Science is due for publication in 1998.
\end{abstract}

